\title{
Black and Tan Coonhound
}

National Cancer Institute

\section{Source}

National Cancer Institute. Black and Tan Coonhound. NCI Thesaurus. Code C53921.

The Black and T an Coonhound is a large, powerful working hound with long pendent ears. A short, sleek, black coat has tan markings on the muzzle, limbs, and chest. The droop of loosely fitting skin and extensive ear leather give the Black and T an a distinctive quality. Height: 23-27 inches (58-68 cm.) Weight: 50-75 pounds (45-64 kg.) 